\title{
Lateral Rotation of the Basal Turn of the Cochlea with its Impact on Cochlear Implant Feasibility
}

\author{
SHERY MIKHAIL, M.Sc.; MAHMOUD F. MANDOUR, M.D.; SAAD EL-ZAYAT, M.D. and \\ MOHAMED HISHAM HAMAD, M.D. \\ The Department of Otolaryngology-Head and Neck Surgery, Faculty of Medicine, Tanta University, Tanta, Egypt
}

\begin{abstract}
Purpose: To investigate variation in cochlear orientation, with respect to rotation of basal turn, and its implication to cochlear implantation.

Methods: Prospective observational study including 25 patients that underwent cochlear implantation at Tanta Cochlear Implant Centre (TCIC), Otolaryngology, Head \& Neck Surgery (ORL-HNS) Department, Faculty of Medicine, Tanta University, that had been done from April 2015 to December 2015, with available charts including Computerized Tomography (C.T.) scan of temporal bone. Axial cut with maximum visualization of the round window was identified, then angle of axial rotation of the cochlea was measured using two methods: Angle 1 between the midline and line through the long axis of the basal turn and angle 2 between the long axis of the basal turn and the long axis of horizontal segment of Internal Carotid Artery (I.C.A.) at the same axial level. All angles were measured using computer software. All cases had cochlear implantation using standard trans-mastoid technique. Round window visibility through facial recess was assessed after maximal widening of the facial recess to achieve best exposure. Then, cases were assigned into one of two groups according to the degree of round window visibility, Group I: Case with full exposed Round Window (R.W.) membrane. Group II: Cases with partially exposed R.W. membrane or invisible R.W. membrane.
\end{abstract}

Results: Following review of the Computed Tomography (CT) images of the two patients (Group II) in whom cochlear implant was difficult. It appeared that the orientation of the basal turn of the cochlea relative to the midline (angle 1) was more obtuse or more acute than in other patients with $p$-value $=0.007 \& 0.002$ respectively. It also showed that the orientation of the basal turn of the cochlear in relation to long axis of horizontal part of internal carotid artery (angle 2) was more obtuse relative to other patient with $p$-value $=0.002 \& 0.001$ respectively.

Conclusion: Our work highlights the importance of preoperative measuring basal turn angel relative to fixed plane, as the mid-sagittal plane in pre-operative CT, instead of other anatomical structure that could be subjected to developmental remodeling and its impact on surgery of cochlear implantation.

Correspondence to: Dr. Shery Mikhail, E-Mail: sherv71325@med.tanta.edu.eg
Key Words: Lateral rotation of the basal turn of the cochlea - Cochlear implant-Cochlear implant feasibility.

\section{Introduction}

NOWADAYS, the concept that the morphological and the spatial orientation of the labyrinth do not undergo post-partum developmental changes is controversial [1]. Current data in the literature regarding cochlear orientation, in particular, is sparse. However, the work of Jeffery and Spoor suggest that there is a significant age-related reduction in the angle of the basal turn of the cochlea relative to the sagittal plane during fetal life [2] More recently, the studies of Erixon et al., [3] and Lloyd et al., [2] drew the attention to examine the angle of basal turn of the cochlea (BTA) to find out its possible clinical impact. Difficult cochleostomy in apparently normal cochlea may be due to cochlear rotation, tilting, or misalignment [1] .

The aim of our study is to investigate variation in axial cochlear orientation represented by the basal turn angulation of the cochlea relative to the mid-sagittal line, to find its possible relationship with the difficulty in implanting normal cochlea and to discuss our results in respects to those of the literature.

\section{Patients and Methods}

This is a prospective observational study, included patients who underwent cochlear implantation at Tanta Cochlear Implant Centre (TCIC), Otolaryngology, Head \& Neck Surgery (ORLHNS) Department, Faculty of Medicine, Tanta University. The hospital is a tertiary institution with a referral status. All Cochlear Implant (CI) cases had been done at the centre from April 2015 to December 2015. 
C.T. scan of each patient was studied. Axial cut with maximum visualization of the round window was identified. Then, angle of axial rotation of the cochlea was measured pre-operatively using radiologic software utilizing two methods:

1- A midline was drawn through the sagittal plane (from the junction of the face of the sphenoid bone and the nasal septum, anteriorly, to the internal occipital protuberance posteriorly) and another line through the long axis of the basal turn. The angle between these bisecting lines then was measured and assigned as "angle 1" Fig. (1).

2- A line was drawn through the long axis of the basal turn and another line through the long axis of horizontal segment of Internal Carotid Artery (ICA) at the same axial level. The angle between these bisecting lines was measured and assigned as "angle 2". Fig. (2).

All cases had cochlear implantation using standard trans-mastoid technique. Round window visibility through facial recess was assessed after maximal widening of the facial recess to achieve best exposure. Then, cases were assigned into one of two groups according to the degree of round window visibility; group I included cases with full exposed Round Window (R.W.) membrane and Group II included cases with partially exposed R.W. membrane or invisible R.W. membrane.

Statistical analysis was done using the Statistical Package of Social Science (SPSS), Version 22 (USA). A one way analysis of variance was used to identify any statistically significant change in basal turn angulation. Inter-and intra-observer errors were calculated and presented as repeatability co-efficients according to the Bland Altmann tech-

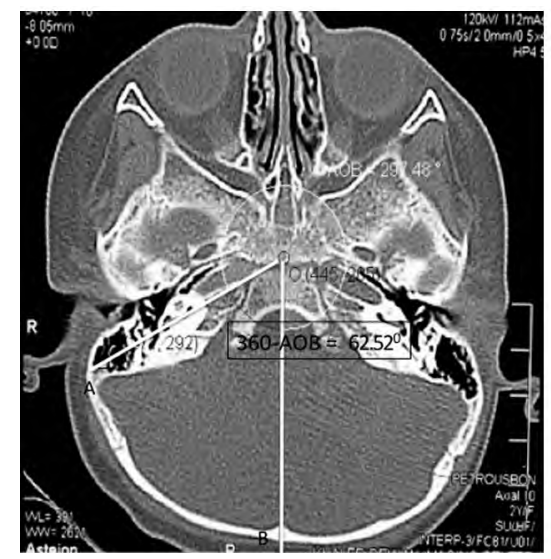

Fig. (1): Method of measuring angle 1 (between the midline and the long axis of the basal turn). nique. The basal turn angles of cases with difficult RWM visualization, Group II, were related to the findings.

\section{Results}

Twenty-five patients have been included in the study with median age of 5ys (range 2-50; mean 11; SD 13.2). The patients was nearly equal distribution in gender for the group of the patients studied where male patients was about $52 \%$.

The mean basal turn angles "angle 1" for right and left ears respectively were $57.9^{\circ}$ (range $44^{\circ}$ $68.8^{\circ}$; SD 4.8 ) and $56.59^{\circ}$ (range $44^{\circ}-68.8^{\circ}$; SD 5.3). The mean value for "angle 2 " for right and left ears respectively were $4.14^{\circ}$ (range $1.4^{\circ}-9.2^{\circ}$; SD 1.95) and $4.52^{\circ}$ (range $2.1^{\circ}-9.2^{\circ}$; SD 1.79).

Following averaging of the right and left basal turn angles for each patient, the mean values for angle $1 \& 2$ respectively were $57.3^{\circ}$ (range 44$68.8^{\circ} ; \mathrm{SD} 4.8^{\circ}$ ) and 4.30 (range 1.750-9.20; SD $1.80)$.

Surgically, twenty-three cases were assigned as Group I (easy round window visualization), and 2 cases were assigned as Group II (difficult visualization). One of these cases had more obtuse basal turn angles than others "angle 1: 68.80 \& angle 2: 9.20" that were at the upper limits of measured ranges. On the other hand, the second case had more acute angle 1 " 440 " that was at the lower limit of measured range. (Table 1).

While angle 2 , as in previous case, was more obtuse than other cases " 8.490 ", that was near upper limit of measured range. (Table 2), Figs. $(3,4)$.

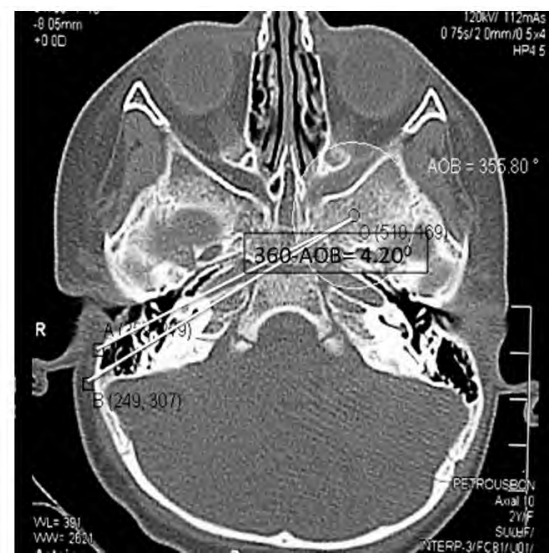

Fig. (2): Method of measuring angle B (between the long axis of the basal turn and the long axis of horizontal segment of Internal Carotid Artery (I.C.A.) at the same axial level. 


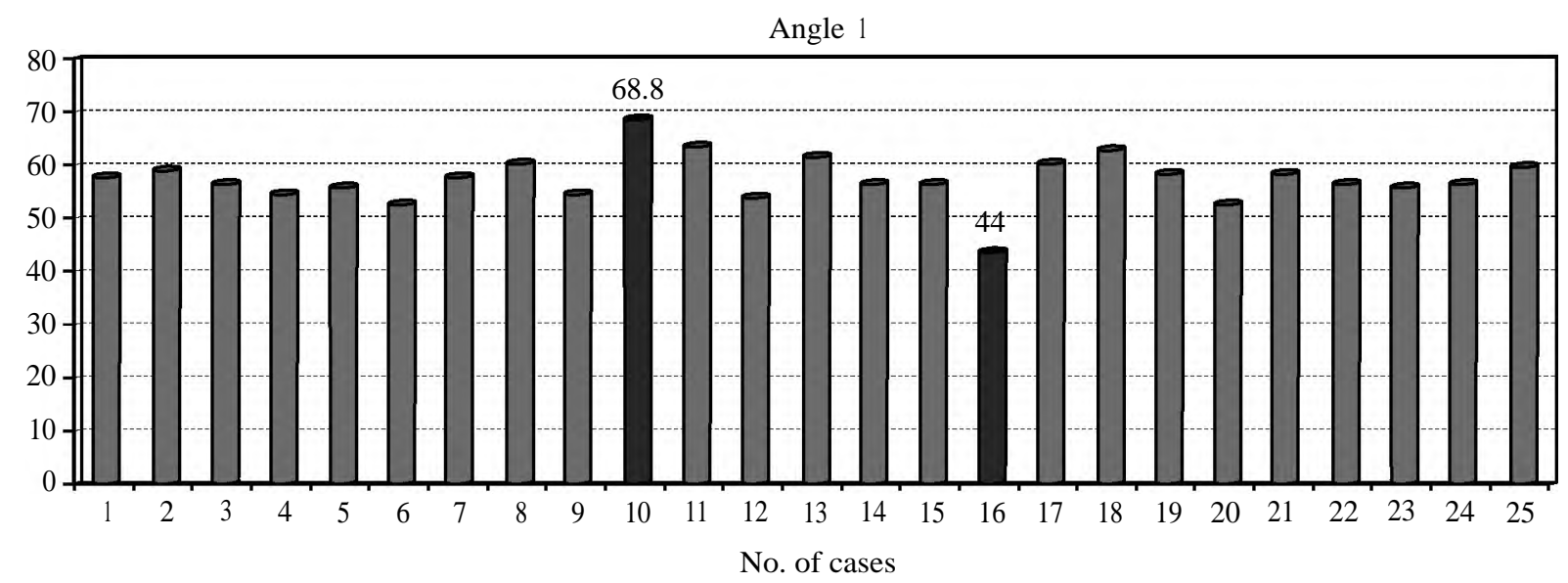

Fig. (3): Angle 1 in the 25 cases. The dark columns show the two cases with difficult round window visualization.

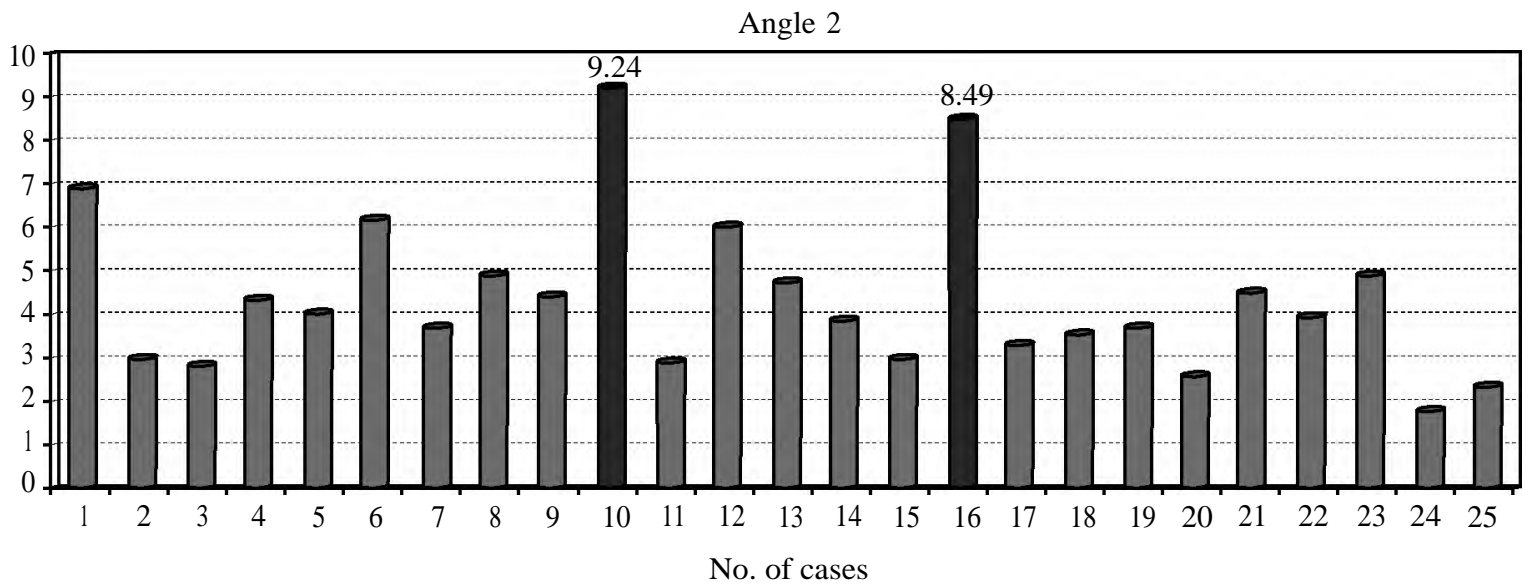

Fig. (4): Angle 2 in the 25 cases. The dark columns show the two cases with difficult round window visualization.

Table (1): Comparison between angle 1 in cases 10,16 in relation to other cases.

\begin{tabular}{cccc}
\hline & Value & $t$ & $p$-value \\
\hline Angle 1 : & & & \\
Case 10 & 68.80 & 2.853 & $0.007^{*}$ \\
Case 16 & 44.00 & 3.360 & $0.002^{*}$ \\
\hline & Mean & \multicolumn{2}{c}{ Std. deviation } \\
\hline All cases & 57.41 & \multicolumn{2}{c}{3.95} \\
\hline
\end{tabular}

\section{Discussion}

The concept that the morphological and the spatial orientation of the labyrinth do not change postnatally is undergoing a worldwide discussion by cochlear implant surgeons. The main objective of this study was to examine the basal turn angulation of the cochlea relative to the mid-sagittal line and long axe of ICA to find a possible relationship with the difficulty in implanting the normal cochlea. Pre-operative imaging analysis was done by measuring two angles; angle "1" (between the
Table (2): Comparison between angle 2 in cases number 10, 16 in relation to other cases.

\begin{tabular}{|c|c|c|c|}
\hline & Mean & $t$ & $p$-value \\
\hline \multicolumn{4}{|l|}{ Angle 2: } \\
\hline Case 10 & 8.49 & 3.215 & $0.002 *$ \\
\hline \multirow[t]{2}{*}{ Case 16} & 9.24 & 3.746 & $<0.001 * *$ \\
\hline & Mean & & Std. deviation \\
\hline All cases & 3.95 & & 1.40 \\
\hline
\end{tabular}

midline and line tangential to the long axis of the basal turn) and angle "2" (between the long axis of the basal turn and the long axis of horizontal segment of internal carotid artery "I.C.A."at the same axial level). We have found that the ranges of values for angle " 1 " and angle " 2 " were 44$68.8^{\circ}$; SD $4.8^{\circ} \& 1.750-9.2^{\circ}$; SD $1.8^{\circ}$ respectively.

Two cases had difficult RWM visualization at surgery. One of them had dorsally rotated cochlea with more obtuse BTA relative to mid-sagittal plane than other cases with easy RWM visualization 
(angle 1: 68.80, at upper limit of measured range), and also more obtuse BTA relative to ICA (angle 2: $9.2^{\circ}$, at upper limit of measured range). The second case had a ventrally rotated cochlea with more acute angle 1 than other cases (440, at lower limit of measured range), and paradoxically slightly more obtuse angle 2 than others $\left(8.5^{\circ}\right.$, near upper limit of measured range).

Although, the literature lacks adequate studies evaluating the axial cochlear rotation, a study by Lloyd et al., was comparable to our work. They had a cross-sectional study of computerized tomography scans of the temporal bones in 159 patients. The angle of the basal turn of the cochlea (BTA) was measured, similar to our protocol, by drawing a line through the long axis of the basal turn and measuring its angle with a line drawn through the mid-sagittal plane. Measured BTAs range was $46.8-63.8^{\circ}$, that were close to the normal range of our study. All cases with difficult RW orientation at surgery had basal turn angles that were at the upper limit of the normal range [2].

Similarly, Al-Muhaimeed HS et al., had a retroprospective descriptive study on two equal groups, each consisting of six cochlear implantees. The Basal Turn Angle (BTA) of the cochlea relative to the mid-sagittal plane was measured using the preoperative axial view of the Computed Tomography $(\mathrm{CT})$ imaging. They reported BTAs (range $=$ $55-60^{\circ}$ ) which were comparable to Lloyd et al., and our results. One case has been reported to have difficult cochleoastomy in whom the BTA was more obtuse than normal $\left(65^{\circ}\right)$. They concluded that the possibility of a rotated cochlea should be borne in mind when difficult cochleostomy is encountered.

Additionally, we have hypothesized that changing in the orientation of basal turn of the cochlea relative to the mid-plane would ultimately affect its orientation to other anatomical structures. Thus, we have attempted to measure the BTA relative to another anatomical landmark as ICA. We have found that normal range for that angle (angle 2) was $1.4-6.7^{\circ}$. One case with difficult RWM visualization had a dorsally rotated cochlea (angle 1: $68.8^{\circ}$ ) and more obtuse angle " 2 " than other cases $\left(9.2^{\circ}\right.$, at upper limit of measured range). The second case with difficult RWM visualization had a relatively ventrally rotated cochlea (angle $1: 44^{\circ}$, at lower limit of measured range) and, unexpectedly, slightly more obtuse angle " 2 " than others $\left(8.5^{\circ}\right.$, near upper limit of measured range).
This finding could be explained by fact that changes in orientation of the basal turn of the cochlea do not reflect remodeling of otic capsule itself but instead result from changes in the morphology of the cranium during post-partum development [4]. So, these changes in the morphology of cranium could affect, not only the otic capsule orientation, but also the whole temporal bone compartments including transverse segment of carotid canal. This could be responsible for keeping nearly constant relation between basal cochlear turn and transverse ICA in spite of changes in orientation of the basal turn. Subsequently, this finding should highlight the significnace of measuring BTA relative to fixed plane, as the midsagittal plane, instead of other anatomical structure that could be subjected to developmental remodeling.

Although, angle "2" was more obtuse in case with dorsally rotated cochlea as well as in case ventrally rotated cochlea, these differences were statistically significant.

To our knowledge, only one study in the literature has utilized the BTA relative to the long axe of transverse portion of ICA to assess the axial rotation of the cochlea. They have reported normal range comparable to our result. However, in our study, we have correlated this method of measuring BTA in addition to the other more common method of Lloyd et al., with the surgical findings.

We believe that further study of lateral and parasagittal cochlear rotation is required to understand its significance particularly on CI. We also would like to highlight the recommendation of Yoo et al., [5] about the feasibility of reconstructed three-dimensional modeling of the cochlea to provide accurate evaluation of cochlear orientation.

\section{Conclusion:}

There is considerable variation in the normal range of cochlear orientation between individuals. Obtuse basal turn angle of the cochlea relative to the mid-sagittal plane more than normal range, indication a dorsally rotated cochlea, should be borne in mind when difficult RWM visualization is encountered. Moreover, acute angulation of the basal cochlear turn "BTA less than normal range", indicating ventrally rotated cochlea, could also be associated with difficult RWM exposure. Measuring the BTA of the cochlea in all preoperative CT scans is advised to identify cases in which the basal turn of the cochlea may have an unusual orientation. 


\section{References}

1- AL-MUHAIMEED H.S. and ABDELWAHED H.Y.: Difficult cochleostomy in the normal cochlea. Egypt J. Otolaryngol., 31: 149-55, 2015.

2- LLOYD S.K., KASBEKAR A.V., KENWAY B., PREVOST T., HOCKMAN M., BEALE T. and GRAHAM J.: Developmental changes in cochlear orientation- implications for cochlear implantation. Otol. Neurotol., 31: 902-7, 2010.

3- ERIXON E., HOGSTROP H., WADIN K. and RASK-
ANDERSEN H.: Variational anatomy of the human cochlea: Implication for cochlear implantation. Otol. Neurotol., 30: 14-22, 2009.

4- FARKAS L.G., POSNICK J.C. and HRECZKO T.M. Jul. Anthropometric growth study of the head. Cleft. Palate. Craniofac. J., 29 (4): 303-8, 1992.

5- YOO S.K., WANG G., RUBINSTEIN J.T. and VANNIER M.W.: Three-dimensional geometric modeling of the cochlea using helico-spiral approximation. IEEE Trans. Biomed. Eng., 47: 1392-402, 2000

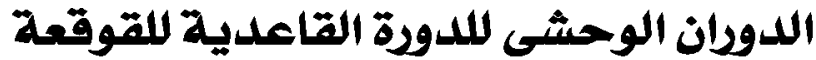

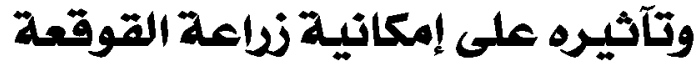

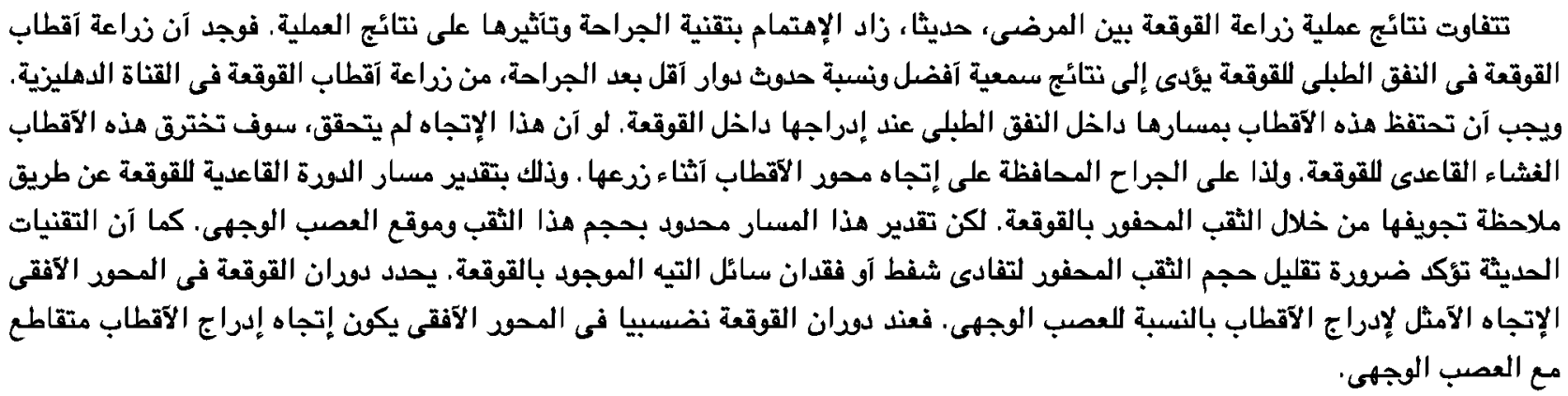

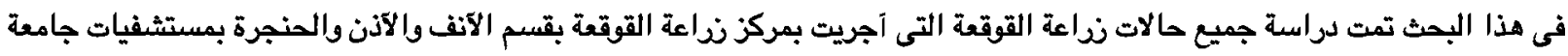

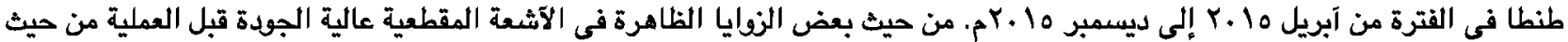

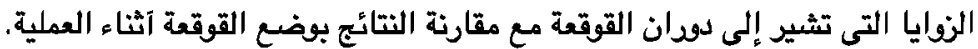

وبمقارنة قيمة الزوايا مع درجة ظهود النافذة الدائرية اللقوقعة وجد حالتين آحدما ذو زاوية حادة بالنسبة للبا قيين والآخرى ذو زاوية منفرجة

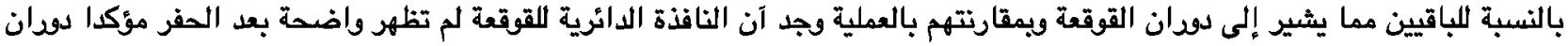
الدوة القاعدية للقوقعة، مما يؤثر على نراعة الآقطاب آثناء عملية نراعة القوقعة. 